\title{
BUDAYA LELUHUR DALAM MEMPERKUKUH TATANAN MASYARAKAT DI ERA GLOBALISASI ${ }^{1}$
}

\author{
ABSTRAK \\ Edhy Rustan ${ }^{2}$ \\ edhy_rustan@yahoo.co.id
}

\begin{abstract}
Nilai-nilai utama kebudayaan lama etnis perlu digali, dikaji dan dipopulerkan kembali sebagai alternatif pengengembangan budaya pada era globalisasi. Tidak ada alternatif lain selain memilih memadukan antara budaya lama atau budaya etnis dengan budaya modern, demi mempertahankan kepribadian bangsa yang asli, namun tetap maju.

Makalah ini mencoba mengambil beberapa kutipan dari naskah kuno (Lontaraq) yang merupakan sumber peninggalan budaya leluhur bangsa Indonesia, khususnya etnis Bugis. Kutipan yang dipaparkan dalam tulisan ini tentunya bersumber dari ideologi kehidupan manusia Bugis pada masa lampau, dan dipandang masih relevan untuk pembangunan kebudayaan masa kini dan di masa depan. Kutipan tersebut menyangkut beberapa aspek, antara lain: aspek kepemimpinan (politik), aspek sosial (kemanusiaan), dan aspek hukum. Selain hal tersebut, dapat diuraiakan nilai utama kebudayaan masyarakat Bugis dalam Lontaraq yang masih dapat dibina dan dipertahankan hingga saat ini, yaitu: amaccang (kecendekiaan); appasitinajang (kepatutan); siri' (rasa malu); lempu (kejujuran); getteng (keteguhan); reso (usaha); awaraningeng (keberanian); dan mapesona ridewatae (berserah diri kepada Sang pencipta).

Memang disadari bahwa pandangan serta penafsiran setiap nilai-nilai utama kebudayaan tersebut senantiasa berubah seiring dengan perkembangan manusia Bugis itu sendiri. Makalah ini tidaklah bermaksud menjelaskan segala hal menyangkut kebudayaan masyarakat Bugis itu sendiri atau menonjolkan suatu etnis tertentu, malainkan hanya bertujuan untuk menunjukkan, bahwa budaya leluhur yang merupakan warisan masyarakat Indonesia, khususnya masyarakat Bugis mengandung banyak manfaat apabila dapat kita jadikan sebagai penuntun dalam kehidupan bersama dalam bingkai NKRI pada era globalisasi. Untuk mencapai tujuan yang dimaksud, perlu dilakukan pelestarian aksara, pengkajian dan penerjemahan budaya lama, serta penghargaan terhadap budaya lama, dan pengaplikasian nilai yang tekandung dengan cara nemadukan dengan budaya modern, agar bangsa ini tetap memiliki jati diri.
\end{abstract}

Kata Kunci: Budaya, Lontaraq, Globalisasi

\section{A. Pendahuluan}

Dalam era globalisasi, kemajuan dalam bidang ilmu pengetahuan dan teknologi telah ikut mempererat hubungan antarbangsa di berbagai sektor kehidupan secara menyeluruh. Di Indonesia khususnya, perkembangan yang berlangsung selama ini telah memacu percepatan proses perubahan sosial budaya dalam kehidupan masyarakat terutama dalam hal akulturasi budaya. Kebudayaan Indonesia yang berkembang selama ini boleh dianggap hampir tidak terkendali. Perubahan mendorong tatanan masyarakat, yang tidak hanya berdampak positif semata; namun juga menimbulkan gejolak sosial yang cenderung mengarah pada timbulnya degradasi moral serta mengaburnya nilai budaya lama bangsa sendiri (Tang, 1992: 1).

Pendidikan budaya yang mengarah pada pemahaman kebudayaan lama (daerah) sudah cukup lama terabaikan. Memudarnya semboyan Bhinneka Tunggal Ika dalam kehidupan berbangsa sebagai akibat pengaruh budaya modern. Kehidupan masyarakat yang individualis dan materialis, demikian kuat mempengaruhi pemikiran masyarakat Indonesia saat ini. Selain hal tersebut, bahaya lain yang kemungkinan akan terjadi yaitu

\footnotetext{
${ }^{1}$ Makalah Disajikan pada Seminar Internasional "Budaya Leluhur dalam Memperkukuh Tatanan Masyarakat di Era Globalisasi” Surabaya 2010

${ }^{2}$ Dosen STAIN Palopo
}

Penyelenggara: Universitas PGRI Adibuana Surabaya, Balai Bahasa Surabaya, dan 
hilangnya nilai budaya leluhur yang merupakan warisan yang amat berharga dan lahirnya sebuah kebudayaan baru yang justru bertentangan dengan kepribadian bangsa sendiri.

Guna melakukan antisipasi berbagai dampak negatif lain yang mungkin timbul, diperlukan sebuah upaya yang terencana dan bijak dalam merancang gerak kebudayaan masa kini dan di masa depan. Salah satu alternatif yang dapat ditempuh adalah membangun sebuah kebudayaan baru yang relevan dengan kepribadian bangsa sendiri. Untuk itu, pembangunan kebudayaan, seharusnya merupakan perpaduan antara budaya setempat yang dikembangkan dari budaya lama dengan budaya luar yang memang tidak mungkin dihindari pengaruhnya. Dengan konsep pembangunan kebudayaan akumulasi seimbang seperti ini, diharapkan kebudayaan bangsa berkembang secara seimbang dalam tatanan kehidupan masyarakat Indonesia yang tetap moderen.

Sumber nilai-nilai utama kebudayaan lama (etnis) hingga kini masih dapat dibaca dalam berbagai naskah kuno (manuscript) yang tersimpan di berbagai tempat. Nilai-nilai utama leluhur tersebut, saat ini sudah jauh dari pemahaman masyarakat sehingga perlu digali dan dipopulerkan, guna dimanfaatkan sebagai dasar pembangunan kebudayaan.

Atas pertimbangan tersebut di atas, maka makalah ini akan mengangkat beberapa pokok pikiran lama manusia Bugis yang diambil dari beberapa 'lontaraq Bugis kuno' yang merupakan sumber peninggalan budaya leluhur bangsa Indonesia khususnya etnis Bugis. Kutipan yang dipaparkan dalam tulisan ini tentunya bersumber dari ideologi kehidupan manusia Bugis pada masa lampau. Pandangan-pandangannya itu tentunya dapat memberi gambaran kepada kita mengenai ideologi yang mereka anut bersama waktu itu dan bagaimana relevansinya dengan pembangunan kebudayaan masa kini dan masa yang akan datang. Selain hal tersebut, makalah ini juga mengurai upayah yang dapat ditempuh dalam memperkukuh tatanan masyarakat di era globalisasi melaui budaya lama.

\section{B. Nilai Utama Kebudayaan Masyarakat Bugis Lampau}

Koentjaraningrat (1988) mengatakan bahwa nilai budaya terdiri atas tingkat pertama kebudayaan ideal atau adat. Nilai budaya merupakan lapisan yang paling abstrak dan ruang lingkupnya sangat luas. Selanjutnya, ia mengatakan bahwa suatu sistem nilai budaya terdiri atas konsepsi-konsepsi yang hidup dalam alam pikiran sebagian besar warga masyarakat, mengenai hal-hal yang harus mereka anggap amat bernilai dalam hidup. Oleh karena itu, suatu sistem nilai budaya biasanya berfungsi sebagai pedoman tertinggi bagi kelakuan manusia.

Tidak dapat dipungkiri bahwa, terdapat nilai-nilai budaya dalam masyarakat Bugis yang tertuang dalam lontaraq yang tidak hanya berbicara tentang masa lampau, tetapi juga dapat dipedomani pada masa kini dan masa yang akan datang. Nilai-nilai yang berkembang hingga saat ini merupakan hasil perenungan yang amat dalam oleh para orang bijak masa lalu dan hal itu dituangkan dalam bentuk petuah (papaseng), falsafah hidup, adat-istiadat (apangadereng) pada aspek kepemimpinan (politik), aspek sosial (kemanusiaan), dan aspek hukum pada Lontaraq.

Rahim (1985) mencatat, terdapat enam nilai utama dalam kebudayaan masyarakat Bugis. Keenam nilai tersebut adalah kejujuran, kecendekiaan, kepatutan, keteguhan, usaha, dan malu. Keenam komponen tersebut merupakan nilai dasar yang berlaku dan berkembang dalam masyarakat Bugis. Sementara itu, Sikki (1991) mencatat 14 nilai budaya yang tersebar pada lima kelompok etnis, yaitu Bugis, Makassar, Mandar, Toraja, dan Massenrempulu. Nilai-nilai itu adalah (1) religi, (2) pendidikan, 
kegotongroyongan, (4) kepemimpinan, (5) persatuan, (6) kejujuran, (7) kecendekiaan, (8) keteguhan, (9) kemanusiaan, (10) kesetiaan, (12) tanggung jawab), (13) kepahlawanan, dan (14) siri'. Apa yang dikemukakan Rahim (1985) dan Sikki (1991) menunjukkan bahwa terdapat sejumlah nilai budaya masyarakat masalampau yang dapat dikaji, dipertahankan dan dijadikan acuan dalam membangun tatanan masyarakat di era globalisasi. Berikut ini diuraikan beberapa contoh.

\section{Kecendekiaan (Amaccang)}

Seorang pemimpin atau tokoh masyarakat, biasanya dipilih dan diangkat atas pertimbangan cerdas dalam masyarakat Bugis. Orang yang cerdas, layak dijadikan panutan orang banyak. Sehubungan dengan hal ini dalam "Lontaraq" H. Andi Ninong dijelaskan:

"Eppai tanranna taue namacca, malempu i namatette; makurang cai $i$; maraddeqna ri gauq sitinajae; makurang pau i ri padanna rupa tau." Dari "Lontaraq" H. Andi Ninong.

(Ada empat ciri orang cerdas, teguh dalam kejujuran; tidang banyak marah; selalu berbuat patut; dan kurang bicara pada sesamanya) (Mahmud, 1976:27).

Dalam masyarakat Bugis, seorang pemimpin atau pemuka masyarakat mutlak harus pintar, hal ini disebabkan karena pada dirinya digantungkan segala harapan dan cita-cita masyarakat. Meskupun demikian, setiap masyarakat juga berkewajiban menjadikan dirinya pintar, baik melalui proses belajar mapun melalui pengalaman.

Orang cerdas juga dapat ditandai dari sikapnya menghadapi orang lain. Orang pintar biasanya tidak banyak bicara, kecuali untuk pembicaraan yang bermanfaat. Hal ini dilakukan karena ia beranggapan bahwa terlalu banyak bicara dapat menyebabkan seseorang menjadi hilaf sehingga pembicaraannya bisa keliru sehingga bisa merugikan diri sendiri maupun orang lain.

\section{Keberanian (Awaraningeng)}

Manusia sempurna dalam pandangan leluhur tidak hanya ia cerdas, tetapi juga harus memiliki keberanian. Bagi mereka keberanian adalah sokoguru bagi seseorang untuk bisa tetap mempertahankan hidupnya dalam upaya menembus ruang dan waktu. Menurut Enre (1992), berani tidak berarti tidak memiliki rasa takut, sebab rasa takut juga merupakan naluri manusia untuk menyelamatkan diri dari ancaman bahaya. Jadi menurutnya, yang disebut berani adalah ketika seseorang mampu menahan atau menekan rasa takut hingga muncul keberanian menanggung resiko demi mempertahankan apa yang diyakininya benar. Demikian pentingnya keberanian itu, dalam lontaraq Andi Makkaraka Ranreng Bettempola (Mahmud, 1976: 60) disebutkan:

"Agguruiwi gauqna tau waranie enrennge ampena. Apaq ia gauqna tau waranie seppuloi uangenna naseua mua jana, jajini asera decenna. Nasabaq ianaro nariaseng jana seddie malomoi naola amatengeng. Naekia mau tau pellorennge mate muto, apak desa temmatena sininna makkenyawae."

(Pelajarilah tingkah laku orang berani. Tingkah laku orang berani ada sepulu macam, namun hanya satu keburukannya, jadi sembilan kebaikannya. Dikatakan satu keburukannya karena mudah menghadapi maut. Namun demikian, orang penakut pun takkan luput dari maut, sebab pastilah mati setiap yang bernyawa).

Menurut Mahmud (1976: 62), pertanda hidup bukanlah sekadar apa yang keluarmasuk dari hidung, tetapi apa yang dipersembahkan. Hidup menghendaki perjuangan yang membutuhkan semangat dan kesediaan berkorban serta menuntut ketabahan. Dengan 
demikian, orang berani adalah orang yang berani berjalan dengan teguh meskipun dalam gempa kehidupan, atau orang yang berani tegak kembali sesudah jatuh.

\section{Kepatutan (Appasitinajang)}

Menurut Rahim (1985: 157), kepatutan merupakan sinonim dari kata kepantasan, atau kelayakan dan merupakan terjemahan dari kata bahasa Bugis 'appasitinajang'. dalam Lontaraq menyebutkan bahwa:

"Potudanngi tudammu; puonroi onrommu"

(duduki kedudukanmu; tempati tempatmu).

Adeq wariq (adat pembedaan) pada hakikatnya mengatur agar segala sesuatu berada pada tempatnya. Mengambil sesuatu dari tempatnya dan meletakkan sesuatu pada tempatnya, termasuk perbuatan appasitinajang. Dan merusak tatatertib ini merupakan kezaliman. Kewajiban yang dibaktikan memperoleh hak yang sepadan adalah suatu perlakuan yang patut. Banyak atau sedikit tidak dipersoalkan oleh sitinaja. Ambil yang sedikit jika yang sedikit itu mendatangkan kebaikan, dan tolak yang banyak apabila yang banyak itu mendatangkan kebinasaan.

\section{Rasa Malu (Siri')}

Secara harfiah siri' berarti malu, juga berarti kehormatan atau harga diri. Ungkapan tau de gaga siri'na dapat dimaknai bahwa orang itu tidak memiliki harga diri. Nilai ini perlu dihayati dan dikembangkan dalam pribadi setiap orang. Siri' merupakan sesuatu yang abstrak dan melembaga di dalam masyarakat dan mencakupi berbagai aspek kehidupan. Perhatikan kutipan berikut.

Tellumpuangengi gauk ri watakkaleta

Seuani, nawa-nawa

Maduanna bicara

(pertama, rencana yang matang)

Matellunna, siri'

Maeppana, gauk madeceng

(kedua, peradilan yang bersih)

(ketiga, harga diri/kehormatan)

Naia peddeenngi nawa-nawae, nakko paccaikcairenngi taue.

Naia peddeenngi bicarae, gauk bawannge.

Naia peddeenngi siri'-e, nakko mangoai taue.

Naia peddeenngi gauk madecennge, nakko taujai padatta tau

(Yang menghancurkan rencana yang matang ialah suka marah.

Yang menghancurkan peradilan ialah kesewenang-wenangan.

Yang menghancurkan harga diri ialah kenginan yang berlebihan.

Yang menghancurkan perbuatan baik ialah menjelekkan sesama manusia).

(Matthes dalam Rahim: 1985: 169).

Siri' harus ditegakkan bersama-sama, secara resiprokal. Ia tidak boleh dipandang hanya kewajiban sepihak, tetapi merupakan tanggung jawab bersama (Rahim, 1985:173). Siri' biasanya dikaitkan dengan hal-hal yang sangat prinsip atau pada hal-hal yang telah menjadi ketentuan dalam masyarakat lalu hal itu dilanggar. Prinsip ini sangat cocok diterapkan dalam menjalankan aturan kenegaraan. Apabilah seorang aparatur negara malu merasa masiri' (malu) kalau berbuat salah maka, tidak akan terjadi pelanggaran hukum.

\section{Keteguhan (Getteng)}

Keteguhan di dalam membela atau mepertahankan prinsip hidup yang diyakini kebenarannya disebut getteng, yaitu suatu prinsip hidup yang menyebabkan seseorang berani berbuat dengan segala resikonya untuk mempertahan sesuatu yang telah digariskan atau disepakati. Dalam ungkapan disebut taro ada taro gauk "satunya kata dan perbuatan". 
Sebuah teks pappaseng dalam lontaraq dilukiskan keteguhan itu sebagai berikut. Pada teks lontaraq digambarkan ciri atau prilaku keteguhan itu seperti berikut.

$\begin{array}{ll}\text { Eppai gaukna gettennge ianaritu: } & \text { (terdapat empat yang menunjukkan keteguhan yaitu:) } \\ \text { tessalaie janci } & \text { (tidak mengingkari janji) } \\ \text { tessorosi ulu ada } & \text { (tidak menghianati keputusan) } \\ \text { tellukkak anu pura } & \text { (tidak membatalkan keputusan) } \\ \text { mabbicarai naparapi } & \text { (berkata benar) }\end{array}$

(Machmud dalam Rahim, 1985: 162)

Dalam bahasa Bugis getteng selain bermakna 'teguh', kata getteng juga bermakna 'taat asas', 'setia pada keyakinan', 'tangguh pada pendirian', dan 'kuat memegang sesuatu' (Rahim, 1985: 160). Jadi, seseorang harus memiliki prinsip yang kuat, yang diyakini kebenarannya di dalam hidup. Dengan prinsip seperti itu seseorang mampu memposisikan diri ke mana Ia harus berada, serta mampu membangun dan merancang masa depan yang lebih bermartabat.

\section{Kejujuran (Lempu)}

Ungkapan dalam lontaraq Bugis menganjurkan seseorang menghindari perbuatan memetik keuntungan dari hasil jerih payah orang lain karena itu perbuatan tidak jujur/curang, seperti bunyi ungkapan berikut:

"Temmasiri kajompie, tania ttaro rampingeng, naia makkalu".

(Tak malu nian si Buncis, bukan ia menyimpang penyanggah, ia yang memanjat)

Oleh karena itu, dalam melakoni kehidupan sehari-hari, masyarakat Bugis diikat oleh norma atau etika yang harus dipatuhi, misalnya tidak boleh mengambil hak orang lain dan merugikan orang lain.

\section{Usaha (Reso)}

Berkerja dengan giat, dalam bahasa Bugis disebut reso. Konsep reso tidak hanya menyangkut materi pekerjaan untuk memenuhi kebutuhan hidup secara peribadi dan keluarga, tetapi lebih dari itu reso merupakan proses pemenuhan kesejahrteraan secara bertangung jawab.

Manusia Bugis pada masa lampau dapat dipandang memiliki penghargaan yang tinggi terhadap waktu dalam kaitan dengan usaha atau kerja keras. Sebagai indikasi ke arah itu dapat dibaca pada catatan La Tadamparek Puang Rimaggalatung, diuraikan sebagai berikut:

"Ee kalaki dega gaga care pallaommu muonro ri sere lalennge? Rekkua degaga laoko ri barugae muengkalinga bicara adek, yarekga laoko ri pasae mengkalinga ada pakbaluk". (Wahai kalian, tidak adakah pekerjaan sampinganmu sehingga engkau tinggal di tepi jalan? Jika tidak ada pergilah ke Balairung mendengar ceramah adat, ataukah engkau ke pasar mendengar warkah penjual (Mahmud, 1975; Rahim, 1985; Ambo Enre, 1992).

Kutipan di atas menyarankan dua harapan dalam bentuk usaha yang masih memiliki relevansi kuat dengan kehidupan manusia Bugis saat ini. Harapan pertama yang disarankan adalah mengenai pentingnya generasi muda bekerja keras mencari nafkah sebagai bekal menghadapi masa depan; tetapi kerja keras dalam mencari nafkah saja tidaklah cukup. Seorang pemuda di samping terampil mencari nafkah, juga padanya diwajibkan menimbah ilmu dari orang lain; baik yang berhubungan dengan pengetahuan umum (di balairung) maupun pengetahuan praktis (di pasar). Dalam berusaha mereka dianjurkan melakukan semua itu dalam dengan ketekunan cita-cita dapat diwujudkan, seperti falsafah Bugis kerja berikut: 
Resopa natinulu malomo naletei pammase Dewata". Hanya kerja yang diiringi ketekunan sering jati titian rahmat Dewata).

Berdasarkan uraian di tasa terdapat hal yang dapat dipetik bahwa berusaha tidak semata bermakna pemenuhan kebutuhan hidup, tetapi berusaha itu adalah bagian dari pengabdian kepada Sang Pencipta. Ini berarti bahwa berusaha menjadi salah satu kewajiban bagi manusia yang harus dilakoni. Satu hal yang pasti bahwa hanya dengan usaha yang sungguh-sungguh "kebahagiaan" dapat dicapai. Oleh karena itu, sesungguhnya minta-minta belas kasih orang lain termasuk tindakan yang tercela dan bertentangan nilai-nilai moral yang berkembang saat sekarang dan tentu juga bertentangan dengan ajaran agama, apa pun.

\section{Berserah Diri pada Sang Pencipta (Mappesona ri Dewatae)}

Catatan dari Arung Matoa Puang ri Maggalatung 1498, yang dikumpulkan Andi Pabarangi mencatat tentang kehidupan yang tetap senantiasa mengingat sang pencipta, seperti kutipan berikut:

"Tellui appongenna decennge: lempue, ianaritu temmelorenngenngi maja padanna rupa tau, temmacinnaienngi waramparanna padanna ripancaji; accae, ianaritu nawa-nawa madecennge ri padanna rupa tau, lamperi toi sungeq, padecengi toi tana totebbeq; metaue ri Dewatae, ianaritu teppoadai belle-belle, tennassurie ada maja ri timunna."

(Ada tiga sumber kebaikan: kejujuran, yaitu tidak menghendaki keburukan sesamanya manusia, tak mengingini milik sesamanya makhluk; kecakapan, yaitu pikiran yang baik terhadap sesamanya manusia, memanjangngkan usia, serta memperbaiki negara dan khalayak ramai; takut kepada Sang Dewata, yaitu tak mengatakan dusta, tak mengucapkan bicara buruk).

Dari kutipan di atas, jelas bahwa pada akhirnya semua bermuara kepada kekuasaan Tuhan sebagai penentu segalanya. Sekali lagi, kejujuran dan kecakapan hanyalah memiliki arti kebaikan bila disandarkan kepada ketentuan Tuhan. Dalam lontaraq juga dibaca bahwa manusia Bugis kuno dalam kepercayaan dianutnya amat menghormati Tuhan yang mereka yakini.

\section{Upayah Memperkukuh Tatanan Masyarakat di Era Globalisasi}

Langkah yang dapat ditempuh untuk memperkukuh tatanan masyarakat di era globalisasi dengan menggunakan budaya lampau sebagai berikut:

\section{Pelestarian Aksara}

Salah satu unsur penunjang dalam pewarisan nilai-nilai budaya melalui pelestarian aksara, merupakan peninggalan masa lalu yang tak ternilai harganya. Tidak semua etnis memiliki aksara tersendiri. Di Indonesia, yang tercatat memiliki aksara hanya beberapa etnis saja. Hal yang pasti adalah etnis yang memiliki aksara berarti memiliki peradaban (masa lalu) yang tinggi. Persoalan yang dihadapi dan perlu dipecahkan adalah kondisi aksara tersebut yang sekarang saat sekarang ini sudah terancam punah. Perlu ada langkahlangkah strategis yang diambil ke depan untuk menyelamatkan aset yang tak ternilai itu. Hal yang dapat dilakasanakan dalam kaitannya dengan pelestarian aksara yaitu bagaimana merancang suatu sistem yang mampu mengakomodasi keinginan atau harapan agar generasi muda dapat berkomunikasi dengan aksara mereka, yang pada gilirannya dapat menggali mutiara-mutiara yang terpendam di dalam budaya lama. Seminar ini perlu mempertimbangkan rekomendasi tentang perlunya pelestarian aksara untuk dikomunikasikan kepada pihak pengambil kebijakan, terutama di bidang pendidikan. 


\section{Pengkajian dan Penerjemahan Budaya Lama}

Setiap etnis memiliki nilai budaya yang dapat dijadikan acuan dalam kehidupan sekarang dan akan datang. Usaha penerjemahan dan penanaman nilai budaya pada generasi yang akan datang perlu digalakkan. Masalah yang dihadapi sekarang adalah kemampuan dan perhatian masyarakat untuk memaknai budaya lama tersebut sangat minim.

Sebagai contoh, terdapat budaya masyarakat Bugis yang tertuang dalam lontaraq, menggunakan wacana implikatur, yang tidak mungkin dapat dipahami dengan tepat kecuali dengan menguasai aksara Lontara bahasa Bugis, seperti:

Duami kuala sappo; Belo-belona kanukue na unganna panasae

[dua saja kujadikan pagar, yaitu cat kuku dan bunga nangka]

Cat kuku itu ialah pacci dan bunga nangka itu ialah lempu. (darwis, 2007)

Dalam aksara Lontara kata pacci dapat dibaca pacci dan dapat pula dibaca paccing. Dalam hal ini lafal kedua yang digunakan, yaitu paccing artinya 'kebersihan'. Kemudian tulisan aksara Lontara lempu dapat dilafalkan lетри dan lетрии. Dalam hal ini, lafal kedua yang dituju, yaitu lетрии artinya kejujuran. Dengan demikian, pagangan hidup masyarakat Bugis ada dua, yaitu bersih dan jujur. Artinya, orang Bugis menjaga citra diri sebagai orang bersih dan jujur.

Berdarkan uraian di atas, agar masyarakat mudah mengaktualisasikan nilai-nilai yang terkandung dalam budaya lama dalam kehidupannya, perlu digalakkan pengkajian dan penerjemahan.

\section{Penghargaan Terhadap Budaya Lama}

Ada beberapa sikap negatif yang dilekatkan kepada budaya lama sehingga budaya cenderung untuk ditinggalkan. Hal ini perlu disadari bersama, agar dapat diusahakan untuk mengubahnya menjadi sikap positif. Pertama, Budaya lama terpandang kuno dan telah menjadi milik masa lampau. Kedua, Budaya lama merupakan budaya orang miskin dan tidak berpendidikan. Ketiga, budaya lama tidak berguna di luar kampung. Keempat, budaya lama menghalangi kemajuan karena terkesan kolot.

Adanya kesan negarif terhadap budaya lama yang kemudian menjadi budaya daerah, perlu dihilangkan dengan usaha meyakinkan bahwa budaya lama merupakan identitas diri yang sangat diperlukan dalam pergaulan nasional dan global. Perlu dipahami bahwa, orang-orang yang maju sekarang adalah orang-orang yang memunyai karakter, budaya, dan sosial. Sebaliknya, orang-orang yang kehilangan identitas karakter, akan terombang-ambing di dalam tatanan nilai globalisasi.

\section{Pengaplikasian Nilai}

Berdasarkan hasil kajian terhadap budaya leluhur, banyak tatanan nilai yang dapat dijadikan acuan dalam menjalankan kehidupan bermasyarakat saat sekarang dan yang akan datang. Berdasarkan kajian yang telah diuraikan di atas terdapat nilai-nilai budaya lampau masyarakat Bugis dalam Lontaraq yang masih dapat dibina dan dipertahankan hingga saat ini. Hal tersebut, berarti terdapat nilai-nilai budaya leluhur pada setiap etnis yang dapat diaplikasikan dalam kehidupan sekarang dan masa yang akan datang.

\section{Penutup}

Jauh dimasa lampau, manusia telah membina dan memelihara kebudayaannya, yang nilainilai utamanya masih terasa melingkupi segenap kehidupan hingga detik ini. Hanya dengan semangat nilai-nilai utama kebudayaan itulah, menyebabkan manusia mampu hidup melampau batas ruang dan waktu. Saat ini, nilai-nilai utama kebudayaan tersebut telah menjadi milik kita bersama sebagai bangsa yang besar.

Seperti halnya dengan budaya leluhur masyarakat Bugis dalam Lontaraq yang masih dapat dibina dan dipertahankan hingga saat ini, yaitu: amaccang (kecendekiaan); appasitinijang 
(kepatutan); awaraningeng (keberanian); siri' (rasa malu); lempu (kejujuran); getteng (keteguhan); reso (usaha); dan mapesona ri Dewatae (berserah diri pada sang Pencipta). Disadari bahwa, pandangan serta penafsiran setiap nilai-nilai kebudayaan senantiasa berubah seiring dengan perkembangan manusia. Makalah ini, tidaklah bermaksud menjelaskan segala hal menyangkut kebudayaan masyarakat Bugis atau menonjolkan suatu etnis tertentu, malainkan hanya bertujuan untuk menunjukkan bahwa, budaya leluhur yang merupakan warisan masyarakat Indonesia, mengandung banyak manfaat apabila diaplikasikan dalam kehidupan bersama dalam bingkai NKRI pada era globalisasi.

Kebudayaan leluhur dari berbagai etnis yang tertuan dalam berbagai naskah pada dasarnya sebagian masih relevan untuk dijadikan sebagai dasar pembangunan kebudayaan masa kini dan masa yang akan datang. Nilai-nilai kebudayaan etnis lama perlu dipertahankan, digali, dikaji, dipopulerkan dan digunakan sebagai alternatif pengengembangan budaya. Tidak ada alternatif lain, kecuali memadukan antara budaya lama atau budaya etnis dengan budaya modern, demi mempertahankan kepribadian bangsa yang asli, namun tetap maju.

\section{DAFTAR PUSTAKA}

Darwis Muhammad. 2007. Hubungan Antara Pemertahanan Bahasa Dan Pemertahanan Budaya: Kasus Bahasa Bugis. Makassar: Balai Bahasa Makassar

Enre, Fachruddin Ambo. 1992. Beberapa Nilai Sosial Budaya dalam Ungkapan dan Sastra Bugis. Pidato Pengukuhan Guru Besar. (dalam Jurnal PINISI, Vol.1). FPBS IKIP Ujung Pandang.

Koentjaraningrat. 1980. Manusia dan Kebudayaan Indonesia. Jakarta: Gramedia.

Mahmud, A. Hasan. 1976. Silasa: Setetes Embun di Tanah Gersang. Ujung Pandang: Yayasan Kebudayaan.

Mattulada. 1995. LATOA: Satu Lukisan Analitis terhadap Antropologi Politik Orang Bugis. Ujung Pandang: Hasanuddin University Press.

Rahim, A. Rahman. 1985. Nilai-nilai Utama Kebudayaan Bugis. Ujung Pandang: Lephas UNHAS.

Sikki, dkk. 1991. Tata Bahasa Bugis. Jakarta: Departemen Pendidikan dan Kebudayaan.

Tang, Muhammad Rapi. 1992. Toloq Rumpakna Bone: Sebuah Telaah Filologis Sastra Bugis Klasik (Tesis Magister). Bandung: Prog. Pascasarjana Universitas Padjadjaran.

2007. Reso adalah Roh Kehidupan Manusia Bugis (Budaya dari Sisi Mental dan Fisik Sebuah Refleksi Dari Lontarak). Makassar: Balai Bahasa Makassar

Tang, Mahmud. 1996. Aneka Ragam Pengaturan Sekuritas Sosial di Bekas Kerajaan Berru Sulawesi Selatan, Indonesia. Wageningen: Lanbouw Universiteit Wageningen. 